\title{
Prescribing Pattern of Hypnotic Medications in Patients Initiating Treatment at Japanese Hospitals: A Nationwide, Retrospective, Longitudinal, Observational Study Using a Claims Database
}

\author{
Ken Inada $^{1}$ (D) Minori Enomoto ${ }^{2}$ (D) $\cdot$ Kentaro Yamato $^{3}$ (D) $\cdot$ Kazuo Mishima $^{4,5,6}$ (D)
}

Accepted: 6 March 2021 / Published online: 13 March 2021

(c) The Author(s) 2021

\begin{abstract}
Background Prolonged treatment of insomnia using benzodiazepine (BZD) receptor agonists, including BZD and non-BZD hypnotic drugs, can cause drug dependence, tolerance, abuse and other adverse events. These side effects are more common and/or severe in older adults taking different hypnotic drugs concomitantly. Therefore, a single prescription is limited to 30 daily doses for most BZD receptor agonists and restrictions apply to the prescription of more than three types of hypnotic drugs in Japan. Little is known, however, about the real-world prescribing pattern of hypnotic drugs in Japan.

Objective We analysed prescribing patterns for hypnotic drugs in Japan to evaluate whether real-world use differs from guideline recommendations.

Methods In this nationwide, retrospective, longitudinal, observational study, we analysed the types of hypnotic drugs prescribed, duration of medication and treatment setting in a subset of hospitals in Japan using a hospital-based administrative claims database (Medical Data Vision). Patients initiating treatment with hypnotic drugs between January 2012 and December 2016 were included in the analyses to assess the duration of medication and occurrence of co-prescription of a second and third hypnotic drug, within a year from prescription of the first hypnotic drugs.

Results In 261,167 patients analysed, the first hypnotic drugs prescribed were BZDs (59.7\%), non-BZDs (36.8\%), a melatonin receptor agonist [MRA] (3.1\%) and an orexin receptor antagonist [ORA] (0.4\%). Benzodiazepine and non-BZD hypnotic drugs were mostly prescribed in inpatient settings $(57.7 \%$ and $63.0 \%$, respectively) and the MRA and ORA mostly in outpatient settings (62.6\% and $65.4 \%$, respectively). The departments that prescribed the most patients their first hypnotic drugs were internal medicine (23.6\%), general surgery (11.8\%), orthopaedic surgery (11.4\%) and urology (5.3\%). Of the total prescriptions of MRA and ORA as the first hypnotic drugs, $22.0 \%$ and $31.8 \%$ were in internal medicine, $4.4 \%$ each in general surgery, $6.0 \%$ and $4.5 \%$ in orthopaedic surgery, $9.7 \%$ and $4.4 \%$ in neurology, and $10.1 \%$ and $12.2 \%$ in psychiatry departments, respectively. Mean duration of medication was 1.13 months for non-BZDs, 1.15 months for BZDs, 1.29 months for the ORA and 1.83 months for the MRA. Overall, 5.3\% (95\% confidence interval 5.2-5.4) of patients were prescribed a second hypnotic drug; of these, 8.4\% (95\% confidence interval 8.0-8.9) were prescribed at least three hypnotic drugs within a year. Patients who were prescribed three or more hypnotic drugs received higher doses of the first drug than patients who received fewer hypnotic drugs.

Conclusions Benzodiazepine receptor agonists were the most common hypnotic drugs prescribed as the first drug to patients in Japan. Further education and awareness may be needed on the risk of complications and adverse events associated with these therapies. The duration of BZD receptor agonist use was shorter than for the MRA and ORA, in accordance with prescribing guidelines. Long-term use and co-prescribing of hypnotic drugs were also uncommon.
\end{abstract}

\section{Introduction}

In clinical practice, insomnia is typically treated with benzodiazepine (BZD) receptor agonists, including BZD and non-

Ken Inada

inada.ken@twmu.ac.jp

Extended author information available on the last page of the article BZD hypnotic drugs [1]. Prolonged use of several hypnotic drugs, including BZD receptor agonists indicated for the treatment of insomnia, can increase the risk of dependence 


\section{Key Points}

The side effects of prolonged benzodiazepine receptor agonist use are more common and/or severe in older adults who take multiple hypnotic drugs concomitantly.

This study revealed that benzodiazepine receptor agonists are the most commonly prescribed first-line treatments and are mostly prescribed in the inpatient setting in hospital departments such as internal medicine, general surgery, orthopaedic surgery and urology.

A melatonin receptor agonist and an orexin receptor antagonist were commonly prescribed to patients in an outpatient setting in internal medicine, psychiatry and neurology departments. (with associated withdrawal and rebound effects), tolerance (potentially necessitating increased dosages) and drug abuse [1-4]. Continued use of hypnotic drugs can also increase the risk of adverse events, such as anterograde amnesia, confusion, somnolence, dizziness, ataxia, fatigue and falls [1, 3 , 5]. These adverse events tend to be more common and/or more severe in older patients and those taking concomitant medications [3]. Thus, many countries, regions/states and institutions do not recommend extended hypnotic drug prescription or co-prescription of multiple psychotropic drugs [3].

The Japanese public health insurance system has restricted both the number of co-prescribed hypnotic drugs and the quantity of a drug in a single prescription [6-8]. Prescribing more than three hypnotic drugs impacts reimbursement, resulting in reduced payment from public health insurance [7]. Up to 30 daily doses of BZDs (except rilmazafone) and a non-BZD hypnotic drug, zolpidem, can be prescribed [6, 8-10]. In contrast, the duration of medication is not restricted for melatonin receptor agonists (MRAs; only ramelteon is available in Japan) or orexin receptor antagonists (ORAs; only suvorexant is approved in Japan) [11]. Thus, the current restriction of hypnotic drugs in Japan applies to the duration of BZD receptor agonist treatment and concomitant use of different drugs.

Data on prescription patterns for hypnotic medications in a real-world setting are limited in Japan [12]. No information is available on MRA and ORA prescription. This study analysed prescribing patterns for hypnotic medications using data from a large Japanese health insurance claims database, covering a subset of hospitals across Japan. We evaluated whether real-world use of hypnotic medication differs from guideline recommendations to detect potential problematic use of BZDs, non-BDZs, MRAs and ORAs.

\section{Methods}

\subsection{Study Design and Setting}

This retrospective longitudinal observational study used data extracted from the Medical Data Vision (MDV) database (Medical Data Vision Co., Ltd, Tokyo, Japan), the largest nationwide hospital-based administrative claims database in Japan. The objective of this study was to explore prescribing patterns for hypnotic medications in Japan, including the prevalence and patterns of co-prescription of different drugs. To capture the prescription pattern of the MRA ramelteon, which became available in Japan in October 2011, data between January 2012 and December 2016 were analysed.

\subsection{Data Source}

The MDV database houses claims data from April 2008 onwards. As of July 2018, the database contained 24 million patient data ( $\sim 19 \%$ of the Japanese population) from 360 large hospitals adopting the Diagnostic Procedure Combination/Per-Diem Payment System, covering 21\% of such hospitals, which comprised about a fifth (in 2019) of all hospitals in Japan. The MDV holds anonymised information about patient characteristics, diagnoses, medical expenses, medical procedures and drug prescriptions. Patient information can be traced over time within the same hospital.

\subsection{Participants}

Eligible patients were observable for at least 3 months before and at least 1 year after the first prescription of a hypnotic drug ("index date"). Those who were prescribed more than one hypnotic drug on the index date or any hypnotic drugs within 3 months of the index date were excluded; a 3-month "washout" was considered sufficient based on typical hypnotic drug prescription durations in Japan. Patients who were prescribed a powder formulation of the first hypnotic drug were also excluded because their dosage was not available in the MDV database.

\subsection{Hypnotic Drugs}

Benzodiazepines included in this study were estazolam, quazepam, triazolam, nitrazepam, nimetazepam, haloxazolam, flunitrazepam, flurazepam, brotizolam, rilmazafone hydrochloride hydrate, lormetazepam and etizolam; non-BZD hypnotic drugs were eszopiclone, zopiclone and 
zolpidem tartrate; the MRA was ramelteon; and the ORA was suvorexant. Melatonin, an MRA that can be purchased over the counter in other countries, is not approved in Japan.

\subsection{Data Analysis}

The following information was retrieved from the database and analysed descriptively: the percentage of patients receiving each drug as their first hypnotic drug prescription, duration of treatment, duration of treatment by treatment setting (inpatient vs outpatient) and hospital department prescribing the first hypnotic drug. Point estimates and $95 \%$ confidence intervals (CIs) were computed for time to second hypnotic drug prescription and its rate of occurrence, and time (from second) to third hypnotic drug prescription and its rate of occurrence. The above data were presented for the overall patient population, by drug class (BZD, non-BZD, MRA and ORA) and by individual hypnotic drugs. Mean changes in monthly dose over time were calculated in all patients, those with a second prescription, those with or without a third prescription, and those with multiple drug types prescribed at the second prescription.

Duration of medication was defined as the time between the index date and the last prescription date of the same drug without any untreated period of more than 60 days; a prescription-free interval of up to 60 days was deemed as continuation of the drug. The maximum number of daily doses allowed in Japan for BZD receptor agonist prescription is $30[6,8,9]$. Treatment duration for patients prescribed a hypnotic medication for more than 1 year was capped at 1 year. Additionally, the proportion of patients who continued the first prescribed hypnotic medication for the entire 1 year after the index date (the "continuation rate") was determined.

The frequency of the second hypnotic drug prescription during the 1 year following the index date was determined, as was the time to the second hypnotic drug prescription (measured from the index date to the date of the first prescription of the second hypnotic drug). Frequency of prescribing at least three hypnotic drugs during the 1 year following the index date was also analysed. For these analyses, patients were classified into three groups, patients prescribed: (1) additional second hypnotic drug without proceeding to a third; (2) additional second hypnotic drug followed by a third (including those who were prescribed additional drugs thereafter); and (3) one or more additional hypnotic drugs prescribed at the time the second hypnotic drug was prescribed. Time from second to third hypnotic drug prescription (measured from first prescription date of the second drug to first prescription date of the third drug) was determined for the second patient group.

A change in the mean monthly dose of prescribed hypnotic medication during the 1 year following the index date was calculated for the three patient groups described above: patients prescribed a single hypnotic drug, two hypnotic drugs or at least three hypnotic drugs. Doses for each drug are expressed as the flunitrazepam-equivalent dose, determined using the conversion table published by Inada and Inagaki [13]. For ramelteon and suvorexant, for which published conversion rates are unavailable, $8 \mathrm{mg}$ and $20 \mathrm{mg}$, respectively, were deemed equivalent to $1 \mathrm{mg}$ of flunitrazepam based on approved doses, clinical experiences of the authors and expert opinion (Dr. Ataru Inagaki, Aoyama Gakuin University, Tokyo, Japan).

All analyses were performed using SAS Version 9.4 (SAS Institute, Cary, NC, USA) and Microsoft Excel (Microsoft, Japan). Data were extracted from the MDV database on 18 November, 2017. Treatment discontinuation was not defined formally in this study. All patient data were de-identified and encrypted before entry into the MDV database.

\section{Results}

\subsection{Patients}

Of $1,785,857$ patients within the MDV Diagnostic Procedure Combination claims database who received at least one prescription for a hypnotic medication within the study timeframe, 261,167 (14.6\%) met the inclusion criteria and were included (Fig. 1). Mean age was 67.1 years; $54.4 \%$ of patients were female (Table 1).

\subsection{First Hypnotic Drug Prescriptions}

Of the 261,167 patients analysed, 59.7\% were prescribed a BZD as the first hypnotic drug, 36.8\% a non-BZD, $3.1 \%$ an MRA (ramelteon) and $0.4 \%$ an ORA (suvorexant) (Table 1).

\subsubsection{Patient Setting}

Overall, 153,841 (58.9\%) of patients had been admitted to hospital at the time of the first hypnotic drug prescription. First hypnotic drugs prescribed in an inpatient setting were BZDs to 89,910 (34.4\%) patients, non-BZDs to $60,525(23.2 \%)$ patients, an MRA to 3048 (1.2\%) patients and an ORA to $358(0.1 \%)$ patients. First hypnotic drugs prescribed in an outpatient setting were BZDs to 65,951 (25.3\%) patients, non-BZDs to 35,596 (13.6\%) patients, an MRA to $5103(2.0 \%)$ patients and an ORA to $676(0.3 \%)$ patients. The BZD and non-BZD hypnotic drugs were mostly prescribed in an inpatient setting $(57.7 \%$ and $63.0 \%$, respectively), whereas the MRA and ORA were mostly prescribed in an outpatient setting $(62.6 \%$ and $65.4 \%$, respectively). Individual drugs that were prescribed to more patients in an inpatient setting than in an outpatient setting 


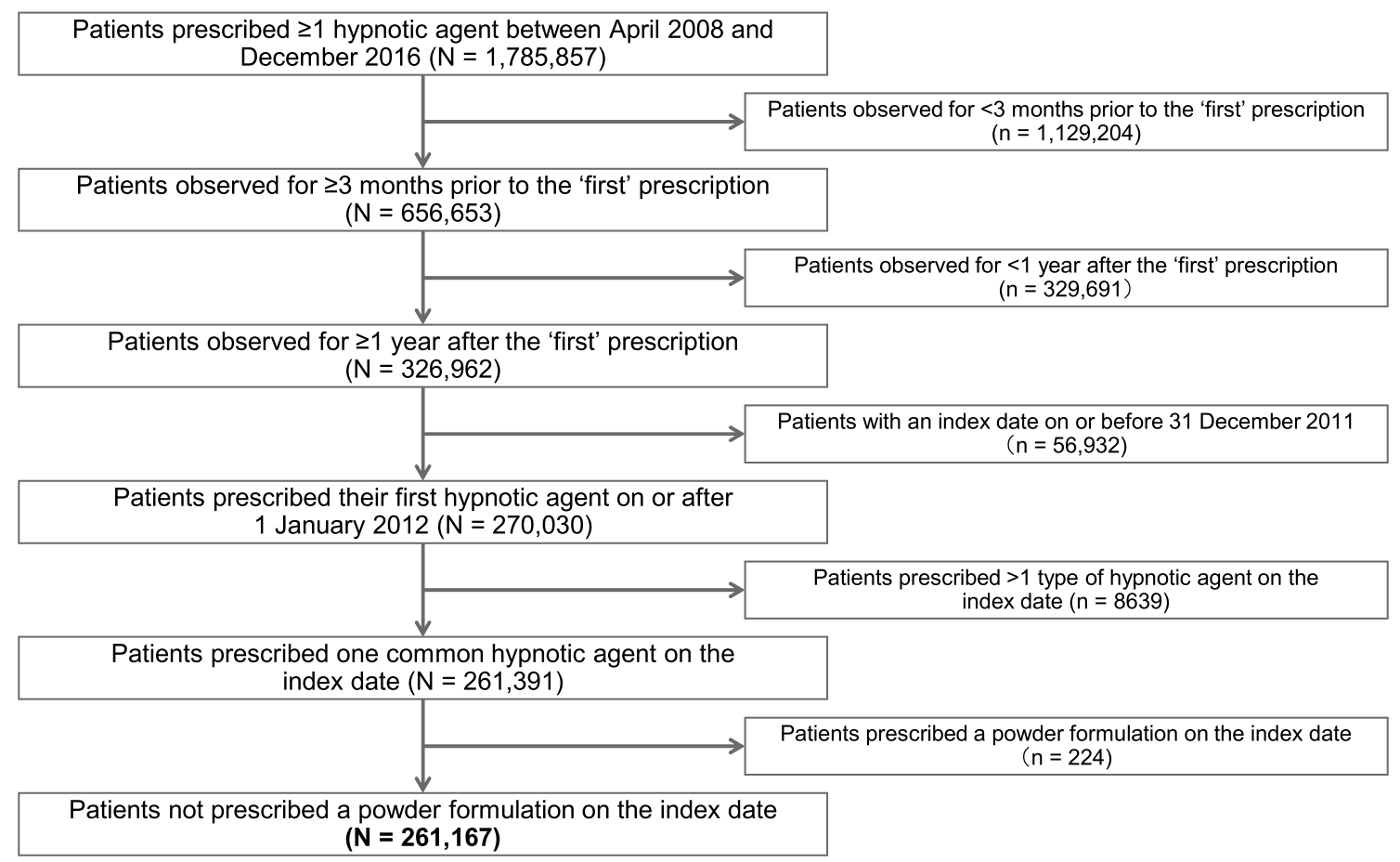

Fig. 1 Patient selection. 'First' prescription defined as the first day of prescription for a hypnotic drug during the observation period

were rilmazafone $(82.0 \%)$, brotizolam $(74.6 \%)$, zopiclone (71.7\%), lormetazepam (66.7\%), nitrazepam (63.7\%), zolpidem (62.7\%), quazepam (61.6\%) and triazolam (54.8\%).

\subsubsection{Medical Departments}

Medical departments prescribing at least $5 \%$ of the total patients $(n=261,167)$ with a first hypnotic drug at the index date included internal medicine (23.6\%), general surgery (11.8\%), orthopaedic surgery (11.4\%) and urology (5.3\%) departments (Fig. 2). Neurology and psychiatry departments (i.e., neurology, psychiatry, neuropsychiatry and psychosomatic medicine) were responsible for prescribing $6.1 \%$ of the first hypnotic drugs in aggregate. Benzodiazepines $(n=$ $155,861)$ and non-BZDs $(n=96,121)$ prescribed as the first hypnotic drugs were similarly distributed across the different departments (Fig. 2). An MRA as the first hypnotic drug ( $=8151)$ was highest in internal medicine $(22.0 \%)$, disproportionally high in psychiatry $(10.1 \%)$ and neurology $(9.7 \%)$ departments, and disproportionally low in other departments including general surgery (4.4\%) and orthopaedic surgery (6.0\%) (Fig. 2). Similarly, ORA as the first hypnotic drug $(n=1034)$ was highest in internal medicine $(31.8 \%)$, disproportionally high in psychiatry $(12.2 \%)$ and disproportionally low in other departments including general surgery (4.4\%), orthopaedic surgery $(4.5 \%)$ and urology $(2.4 \%)$ (Fig. 2). The distribution of individual BZD and non-BZD drugs prescribed as the first hypnotic drug across different departments had a similar profile as that of the whole drug class (Table 2).

\subsubsection{Mean Duration of Prescribed Treatment}

Mean duration of prescribed treatment with a first hypnotic drug was 1.16 months. Individual BZDs and non-BZDs prescribed first for a mean of over 1 month were flurazepam, estazolam, triazolam, etizolam, lormetazepam, eszopiclone, nitrazepam, brotizolam and zolpidem (Table 1); mean duration was 1.15 months for BZDs and 1.13 months for nonBZDs overall. The MRA and ORA were prescribed for a mean of 1.83 and 1.29 months, respectively.

\subsubsection{Continuation Rate}

The continuation rate of hypnotic drugs was $4.7 \%(n=$ 12,340) (Table 1). For the MRA, the continuation rate was higher than that observed with other drug classes $(7.9 \%$ vs $4.4-5.2 \%)$.

\subsection{Further Hypnotic Drug Prescriptions}

In total, 13,799 patients (5.3\%) were prescribed a second hypnotic drug within 1 year after the index date (Table 1). Patients prescribed an MRA as the first drug were more frequently prescribed a second hypnotic drug than were those prescribed other drug classes (8.3\% vs 5.1-6.0\%) (Table 1). 
Table 1 Summary of patient age and sex at the time of first hypnotic drug prescription (index date), and first and second hypnotic drug prescriptions, overall and according to drug class and drug

\begin{tabular}{|c|c|c|c|c|c|c|c|c|}
\hline $\begin{array}{l}\text { First drug } \\
\text { received }\end{array}$ & Patients, $n(\%)$ & $\begin{array}{l}\text { Mean age, } \\
\text { years (SD) }\end{array}$ & Female, $\%$ & $\begin{array}{l}\text { Quantity limit } \\
\text { for a single } \\
\text { prescription }^{\mathrm{a}}\end{array}$ & $\begin{array}{l}\text { Mean dura- } \\
\text { tion of first } \\
\text { hypnotic drug } \\
\text { prescription, } \\
\text { months }\end{array}$ & $\begin{array}{l}\text { First hypnotic } \\
\text { drug continu- } \\
\text { ation rate, \% } \\
(95 \% \mathrm{CI})\end{array}$ & $\begin{array}{l}\text { Second } \\
\text { hypnotic drug } \\
\text { prescription, } \\
\%(95 \% \mathrm{CI})\end{array}$ & $\begin{array}{l}\text { Mean time to } \\
\text { second hypnotic } \\
\text { drug prescrip- } \\
\text { tion, months } \\
(95 \% \mathrm{CI})\end{array}$ \\
\hline Total & 261,167 & $67.1(15.5)$ & 54.4 & - & 1.16 & $4.7(4.6-4.8)$ & $5.3(5.2-5.4)$ & $\begin{array}{l}1.24(1.20- \\
1.28)\end{array}$ \\
\hline BZDs & $155,861(59.7)$ & & & - & 1.15 & $4.8(4.7-4.9)$ & $5.1(5.0-5.2)$ & $\begin{array}{l}1.26(1.21- \\
1.31)\end{array}$ \\
\hline Brotizolam & $63,200(24.2)$ & $68.7(14.5)$ & 50.5 & $\begin{array}{l}1 \text { month's } \\
\text { supply }\end{array}$ & 1.22 & $5.0(4.8-5.1)$ & $6.0(5.8-6.1)$ & $\begin{array}{l}1.20(1.13- \\
1.26)\end{array}$ \\
\hline Etizolam & $39,181(15.0)$ & $65.0(16.5)$ & 64.5 & $\begin{array}{l}1 \text { month's } \\
\text { supply }\end{array}$ & 1.53 & $6.7(6.4-6.9)$ & $4.7(4.5-4.9)$ & $\begin{array}{c}1.68(1.57- \\
1.80)\end{array}$ \\
\hline $\begin{array}{l}\text { Flunitraz- } \\
\text { epam }\end{array}$ & $20,083(7.7)$ & $66.9(14.6)$ & 45.5 & $\begin{array}{l}1 \text { month's } \\
\text { supply }\end{array}$ & 0.51 & $2.0(1.8-2.2)$ & $3.8(3.5-4.1)$ & $\begin{array}{c}0.97(0.84- \\
1.11)\end{array}$ \\
\hline Rilmazafone & $19,542(7.5)$ & $66.0(15.1)$ & 54.9 & No limit & 0.58 & $1.5(1.4-1.7)$ & $3.8(3.5-4.1)$ & $\begin{array}{c}0.75(0.64- \\
0.86)\end{array}$ \\
\hline Triazolam & $7839(3.0)$ & $68.2(14.7)$ & 57.7 & $\begin{array}{l}1 \text { month's } \\
\text { supply }\end{array}$ & 1.55 & $7.6(7.0-8.2)$ & $5.7(5.2-6.2)$ & $\begin{array}{l}1.29(1.10- \\
1.48)\end{array}$ \\
\hline Nitrazepam & $2693(1.0)$ & $63.0(18.8)$ & 61.0 & $\begin{array}{l}1 \text { month's } \\
\text { supply }\end{array}$ & 1.26 & $5.1(4.3-6.0)$ & $5.9(5.0-6.8)$ & $\begin{array}{l}1.33(0.98- \\
1.69)\end{array}$ \\
\hline $\begin{array}{l}\text { Lormetaz- } \\
\text { epam }\end{array}$ & $1524(0.6)$ & $69.7(14.2)$ & 50.1 & $\begin{array}{l}1 \text { month's } \\
\text { supply }\end{array}$ & 1.51 & $6.7(5.4-7.9)$ & $5.2(4.1-6.4)$ & $\begin{array}{c}1.78(1.15- \\
2.40)\end{array}$ \\
\hline Estazolam & $1354(0.5)$ & $69.3(15.3)$ & 51.7 & $\begin{array}{l}1 \text { month's } \\
\text { supply }\end{array}$ & 1.79 & $8.3(6.8-9.7)$ & $8.1(6.6-9.5)$ & $\begin{array}{c}1.18(0.81- \\
1.56)\end{array}$ \\
\hline Quazepam & $424(0.2)$ & $61.7(16.5)$ & 62.3 & $\begin{array}{l}1 \text { month's } \\
\text { supply }\end{array}$ & 0.84 & $3.3(1.6-5.0)$ & $4.5(2.5-6.5)$ & $\begin{array}{c}0.91(0.14- \\
1.68)\end{array}$ \\
\hline $\begin{array}{l}\text { Nimetaz- } \\
\text { epam }\end{array}$ & $11(<0.1)$ & $60.3(18.7)$ & 27.3 & $\begin{array}{l}1 \text { month's } \\
\text { supply }\end{array}$ & 0.43 & 0 & 0 & N/A \\
\hline Flurazepam & $7(<0.1)$ & $62.0(11.0)$ & 42.9 & $\begin{array}{l}1 \text { month's } \\
\text { supply }\end{array}$ & 1.97 & $\begin{array}{c}14.3(0.0- \\
40.2)\end{array}$ & 0 & N/A \\
\hline Haloxazolam & $3(<0.1)$ & $59.7(6.6)$ & 100 & $\begin{array}{l}1 \text { month's } \\
\text { supply }\end{array}$ & 0.03 & 0 & 0 & N/A \\
\hline Non-BZDs & $96,121(36.8)$ & & & - & 1.13 & $4.4(4.3-4.5)$ & $5.3(5.2-5.5)$ & $\begin{array}{l}1.18(1.12- \\
1.23)\end{array}$ \\
\hline Zolpidem & $72,354(27.7)$ & $67.0(16.5)$ & 53.1 & $\begin{array}{l}1 \text { month's } \\
\text { supply }\end{array}$ & 1.14 & $4.4(4.3-4.6)$ & $5.2(5.0-5.4)$ & $\begin{array}{l}1.20(1.14- \\
1.27)\end{array}$ \\
\hline Zopiclone & $17,713(6.8)$ & $68.4(14.3)$ & 54.9 & No limit & 1.00 & $3.7(3.4-4.0)$ & $5.9(5.5-6.2)$ & $\begin{array}{c}0.94(0.83- \\
1.06)\end{array}$ \\
\hline Eszopiclone & $6054(2.3)$ & $68.4(15.0)$ & 55.3 & No limit & 1.44 & $5.9(5.3-6.5)$ & $5.4(4.8-6.0)$ & $\begin{array}{c}1.59(1.34- \\
1.84)\end{array}$ \\
\hline \multicolumn{9}{|l|}{ MRA } \\
\hline Ramelteon & $8151(3.1)$ & $65.2(23.0)$ & 49.7 & No limit & 1.83 & $7.9(7.3-8.5)$ & $8.3(7.7-8.9)$ & $\begin{array}{c}1.47(1.30- \\
1.65)\end{array}$ \\
\hline \multicolumn{9}{|l|}{ ORA } \\
\hline Suvorexant & $1034(0.4)$ & $67.3(16.3)$ & 51.5 & No limit & 1.29 & $5.2(3.9-6.6)$ & $6.0(4.5-7.4)$ & $\begin{array}{c}1.35(0.84- \\
1.86)\end{array}$ \\
\hline
\end{tabular}

$B Z D$ s benzodiazepines, $C I$ confidence interval, $M R A$ melatonin receptor agonist, $N / A$ not applicable, $O R A$ orexin receptor antagonist, $S D$ standard deviation

${ }^{a}$ According to the Japanese Ministry of Health, Labour and Welfare[8] 


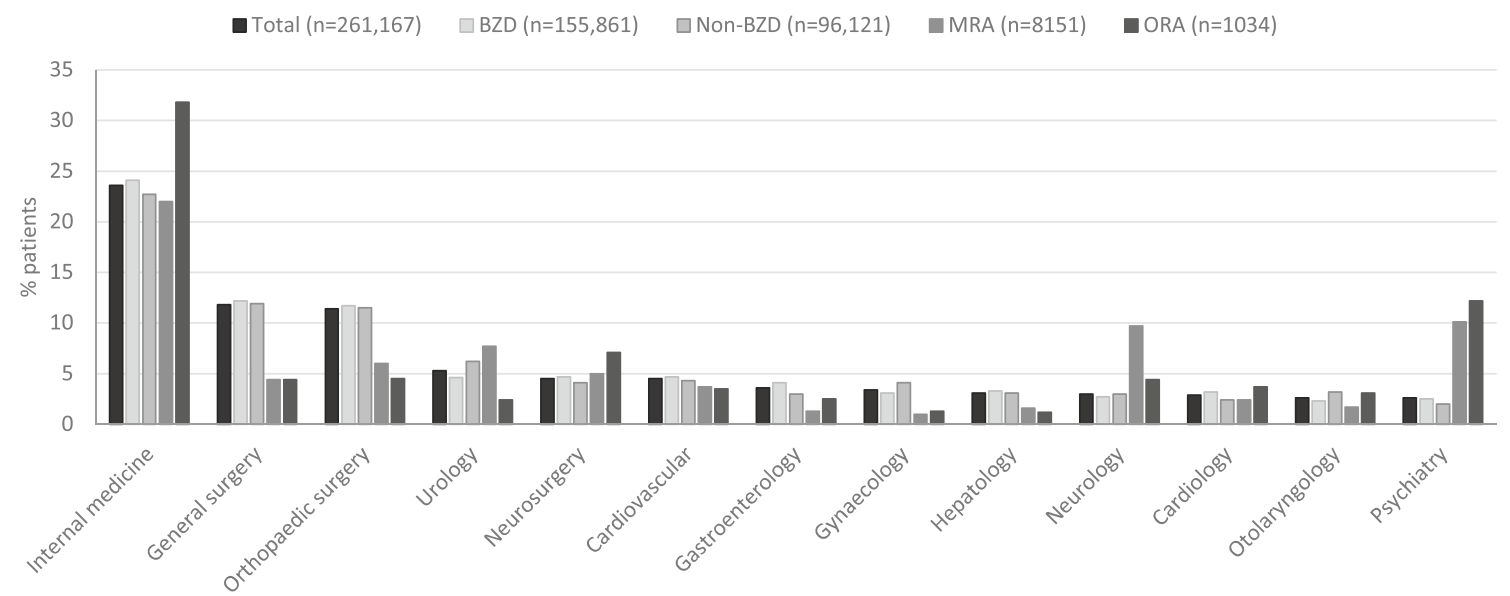

Fig. 2 Percentage of patients with a first hypnotic drug prescription by medical department, overall and according to drug class. Only medical departments issuing at least $2 \%$ of prescriptions are shown. Total prescriptions by additional neurology and psychiatry depart- ments were as follows: psychosomatic medicine (0.2\%), neuropsychiatry $(0.2 \%)$ and undefined neurology department $(0.1 \%)$. BZD benzodiazepine, $M R A$ melatonin receptor agonist, $O R A$ orexin receptor antagonist
However, time until prescription of a second hypnotic drug was similar in patients prescribed an MRA as their first drug compared with those prescribed other drug classes (1.47 vs 1.18-1.35 months) (Table 1).

Of 13,799 patients prescribed a second drug, $1163(8.4 \%)$ were prescribed at least three drugs (Table 3 ). Patients initially prescribed an ORA were overall most likely to be prescribed at least three drugs and those prescribed a non-BZD were least likely to be prescribed at least three drugs.

The mean time from the second to third hypnotic drug prescription was 0.92 months among 807 patients prescribed a single second hypnotic drug followed by a third drug (Table 4). The time from the second to third prescription was longer in patients initially prescribed an MRA than those first prescribed another hypnotic drug class (1.35 vs 0.43-0.94 months).

The mean monthly dose of a prescribed hypnotic medication increased almost linearly over the 1-year post-index period (Fig. 3). At all timepoints, the mean monthly dose was higher in patients receiving three or more medications than in those receiving fewer medications.

\section{Discussion}

We used the largest hospital-based health claim database in Japan to analyse real-world prescribing patterns of hypnotic medications. Our findings revealed a wide range of drugs prescribed as initial hypnotic medications, with BZDs the most commonly prescribed ( $\sim 60 \%$ of patients). The second most common class was non-BZDs, prescribed to over onethird of patients. First use of the MRA ramelteon $(3.1 \%)$ and the ORA suvorexant $(0.4 \%)$ was uncommon. The most prescribed drug was the non-BZD zolpidem (27.7\%). Thus, hospital physicians in Japan appear to prefer BZDs and nonBZDs as the first hypnotic drug, despite the risk of complications and associated adverse events [1-5].

Our findings are consistent with those from a cross-sectional study in Japanese adults with insomnia from the 2012 Japan National Health and Wellness Survey [14], which reported BZDs and non-BZDs (zolpidem, brotizolam, flunitrazepam, etizolam and triazolam) as the most commonly prescribed hypnotic drugs. Similar trends were reported in studies in the USA, Taiwan, South Korea, France and Switzerland [15-19]. Thus, the high prevalence of BZD receptor agonist prescription remains a challenge in public health systems worldwide.

Approximately $60 \%$ of patients were inpatients at the time of the first hypnotic drug prescription. Of all hypnotic drugs reported, rilmazafone, brotizolam, zopiclone, lormetazepam, nitrazepam, zolpidem, quazepam and triazolam were prescribed to more inpatients than to outpatients. By contrast, ramelteon and suvorexant were more frequently prescribed to outpatients. Internal medicine was the department with the highest rate of prescription of first hypnotic medications. This is not surprising, as those having health problems in Japan would initially visit hospital internists in general, as consultation with a primary care physician is not mandatory. A prior study on outpatients attending a Japanese hospital indicated that BZDs were most likely to be prescribed to patients treated in internal medicine departments compared with other hospital departments [20]. In our analysis, higher proportions of MRA (ramelteon) and ORA (suvorexant) drugs among the total prescription of each drug 


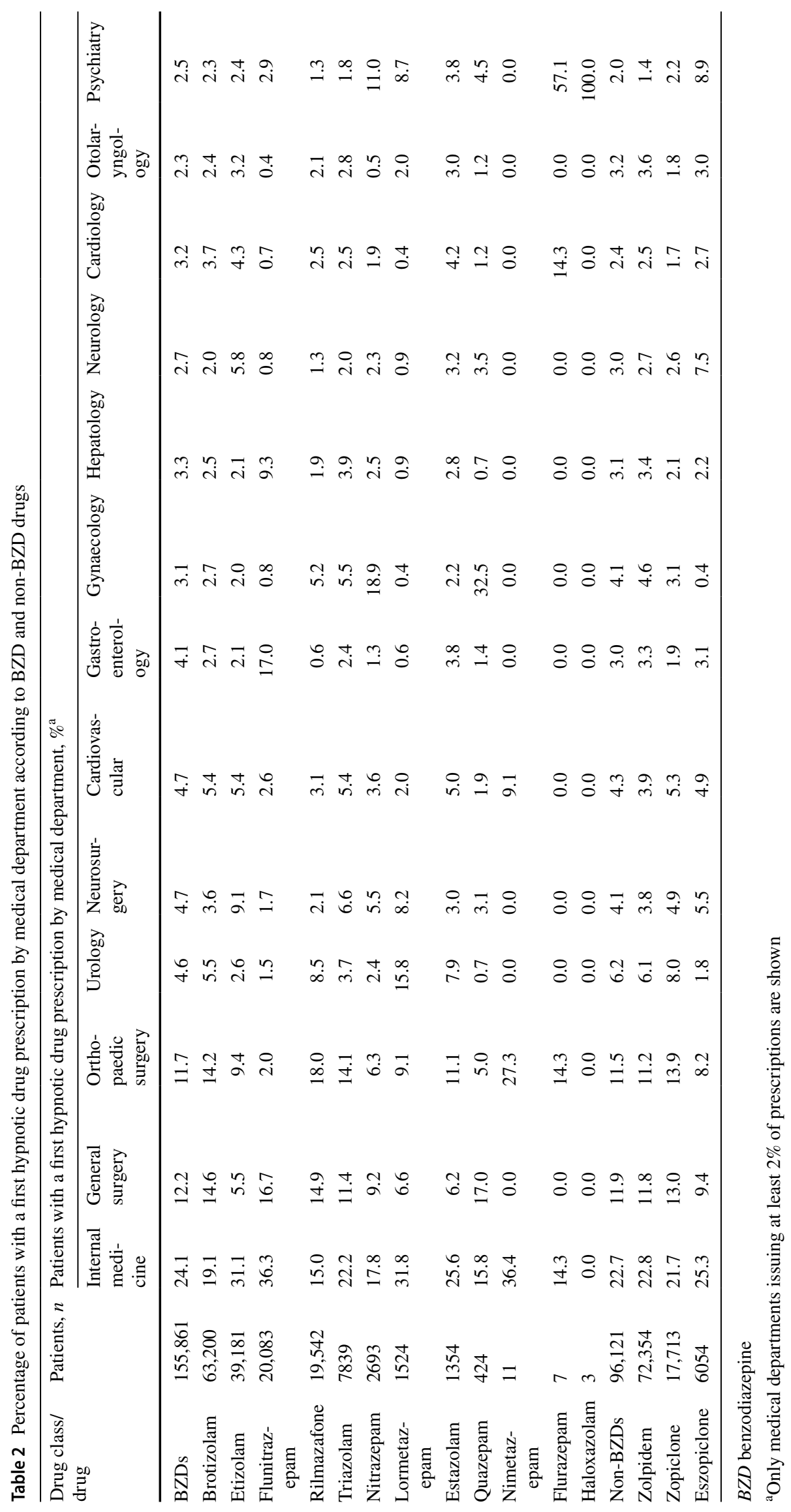


Table 3 Trends in second and subsequent hypnotic drug prescriptions according to drug class and drug

\begin{tabular}{|c|c|c|c|c|c|}
\hline \multirow[t]{2}{*}{ Drug class/drug } & \multirow{2}{*}{$\begin{array}{l}\text { Patients with second } \\
\text { prescription, } n\end{array}$} & \multicolumn{4}{|c|}{ Subsequent hypnotic drug prescriptions } \\
\hline & & $\begin{array}{l}\text { No additional drug after } \\
\text { second drug, } \%\end{array}$ & $\begin{array}{l}\text { Third drug after sec- } \\
\text { ond drug, } \%\end{array}$ & $\begin{array}{l}\text { Multiple drugs }{ }^{\mathrm{a}} \text {, } \\
{ }^{2}\end{array}$ & $\begin{array}{l}\text { Prescribed } \geq 3 \\
\text { drugs in total, \% } \\
(95 \% \mathrm{CI})\end{array}$ \\
\hline Total & 13,799 & 91.6 & 5.8 & 2.6 & $8.4(8.0-8.9)$ \\
\hline BZDs & 7928 & 91.2 & 6.1 & 2.7 & $8.8(8.2-9.4)$ \\
\hline Brotizolam & 3764 & 92.1 & 5.6 & 2.3 & $7.9(7.0-8.8)$ \\
\hline Etizolam & 1850 & 92.7 & 5.2 & 2.1 & $7.3(6.1-8.5)$ \\
\hline Flunitrazepam & 762 & 84.9 & 9.6 & 5.5 & $15.1(12.6-17.6)$ \\
\hline Rilmazafone & 741 & 92.2 & 6.2 & 1.6 & $7.8(5.9-9.8)$ \\
\hline Triazolam & 444 & 87.6 & 6.8 & 5.6 & $12.4(9.3-15.5)$ \\
\hline Nitrazepam & 159 & 89.9 & 6.9 & 3.1 & $10.1(5.4-14.7)$ \\
\hline Estazolam & 109 & 89.0 & 8.3 & 2.8 & $11.0(5.1-16.9)$ \\
\hline Lormetazepam & 80 & 91.3 & 6.3 & 2.5 & $8.8(2.6-14.9)$ \\
\hline Quazepam & 19 & 89.5 & 10.5 & 0.0 & $10.5(0.0-24.3)$ \\
\hline Flurazepam & 0 & 0.0 & 0.0 & 0.0 & 0 \\
\hline Haloxazolam & 0 & 0.0 & 0.0 & 0.0 & 0 \\
\hline Nimetazepam & 0 & 0.0 & 0.0 & 0.0 & 0 \\
\hline Non-BZDs & 5136 & 92.2 & 5.4 & 2.4 & $7.8(7.1-8.5)$ \\
\hline Zolpidem & 3766 & 92.4 & 5.2 & 2.4 & $7.6(6.8-8.5)$ \\
\hline Zopiclone & 1043 & 92.8 & 5.0 & 2.2 & $7.2(5.6-8.8)$ \\
\hline Eszopiclone & 327 & 88.4 & 8.9 & 2.8 & $11.6(8.1-15.1)$ \\
\hline \multicolumn{6}{|l|}{ MRA } \\
\hline Ramelteon & 673 & 91.1 & 6.5 & 2.4 & $8.9(6.8-11.1)$ \\
\hline \multicolumn{6}{|l|}{ ORA } \\
\hline Suvorexant & 62 & 90.3 & 4.8 & 4.8 & $9.7(2.3-17.0)$ \\
\hline
\end{tabular}

$B Z D$ s benzodiazepines, $C I$ confidence interval, $M R A$ melatonin receptor agonist, $O R A$ orexin receptor antagonist

${ }^{\text {a } P r e s c r i b e d ~ c o n c o m i t a n t l y ~ a t ~ t h e ~ t i m e ~ o f ~ t h e ~ s e c o n d ~ h y p n o t i c ~ d r u g ~ p r e s c r i p t i o n ~}$

were prescribed in psychiatry and neurology/neurosurgery departments than BZDs and non-BZDs. This finding may reflect the minimal abuse potential of MRAs and ORAs and relatively benign neuropsychiatric side-effect profiles [1, $4,5]$, which are common for patients with brain injury or psychiatric conditions [21,22]. Targeted detailing of these drugs in psychiatry and neurology/neurosurgery departments by the manufacturers may also be a factor. The choice of hypnotic drug was reported to be influenced by physician specialty, duration of effect, patient age, comorbidities and cost [23-25]. Further education and awareness campaigns may be needed around the risk of complications and adverse events associated with these therapies [26, 27].

Long-term use of some BZDs and non-BZDs is concerning and may represent a public health problem in Japan and other countries [28-36]. Internists and psychiatrists in Japanese hospitals may be more likely to prescribe long-term hypnotic medications than physicians of other specialities $[25,34,36]$, possibly because psychiatric patients have a higher rate of chronic insomnia than the general population $[5,21]$. The MRA ramelteon has a lower risk of cumulative adverse events than most other hypnotic drugs $[1,4,5,10$, 37], and thus may be suitable for extended use in adults. Patients prescribed an MRA as the first drug had a higher rate $(7.9 \%)$ of continuing the therapy for at least 1 year than the overall patient population (4.7\%). Despite a low continuation rate among initiators of hypnotic drugs, the estimated prevalence of hypnotic drug use is high in the Japanese population overall $(3.02 \%$ in male individuals and $4.29 \%$ in female individuals) [38].

Overall, 13,799 (5.3\%) patients were prescribed a second hypnotic drug during the follow-up period (1 year following study entry); of these, 1163 (8.4\%) were prescribed at least three drugs. Effective first hypnotic drug treatment, along with treatment guidelines that warn against co-prescription of psychotropic drugs, may explain the low use of additional hypnotic drugs. The Pharmaceuticals and Medical Devices Agency in Japan published an Alert for Proper Use of Drugs for BZD receptor agonists in March 2017 [39], closely following the observation period of this study (December 2016), which may further reduce co-prescriptions or prolonged or high-dose prescriptions of BZD 
Table 4 Time from second to third hypnotic drug prescription in patients prescribed second and third drugs sequentially, overall, and by drug and drug class

\begin{tabular}{lll}
\hline $\begin{array}{l}\text { First hypnotic } \\
\text { drug prescrip- } \\
\text { tion }\end{array}$ & Patients, $n$ & $\begin{array}{l}\text { Mean time from second to third } \\
\text { hypnotic drug prescription, months } \\
(95 \% \text { CI })\end{array}$ \\
\hline Total & 807 & $0.92(0.81-1.03)$ \\
BZDs & 483 & $0.94(0.80-1.09)$ \\
Brotizolam & 211 & $0.97(0.75-1.20)$ \\
Etizolam & 96 & $0.97(0.66-1.28)$ \\
Flunitrazepam & 73 & $1.20(0.74-1.66)$ \\
Rilmazafone & 46 & $0.42(0.20-0.65)$ \\
Triazolam & 30 & $0.94(0.51-1.36)$ \\
Nitrazepam & 11 & $1.00(0.00-2.03)$ \\
Estazolam & 9 & $0.30(0.10-0.50)$ \\
Lormetazepam & 5 & $0.82(0.00-1.88)$ \\
Quazepam & 2 & $2.06(0.00-4.45)$ \\
Flurazepam & 0 & N/A \\
Haloxazolam & 0 & N/A \\
Nimetazepam & 0 & N/A \\
Non-BZDs & 277 & $0.81(0.63-0.98)$ \\
Zolpidem & 196 & $0.83(0.60-1.06)$ \\
Zopiclone & 52 & $0.51(0.27-0.74)$ \\
Eszopiclone & 29 & $1.17(0.68-1.67)$ \\
MRA & & $1.35(0.73-1.98)$ \\
Ramelteon & 44 & $0.43(0.11-0.75)$ \\
ORA & & \\
Suvorexant & 3 & \\
\hline
\end{tabular}

$B Z D s$ benzodiazepines, $C I$ confidence interval, MRA melatonin receptor agonist, $N / A$ not applicable, $O R A$ orexin receptor antagonist

hypnotic drugs in Japan. Patients prescribed an MRA first were marginally more likely to be prescribed a second drug than those prescribed other drug classes. However, the time until prescription of a second hypnotic drug was longer in patients prescribed an MRA first. Patients prescribed an ORA first were most likely to be prescribed at least three drugs. Patients prescribed at least three drugs had a higher mean monthly dose than those prescribed fewer drugs.

Our study showed that the mean monthly dose of prescribed hypnotic medication increased with time. The increases likely reflect the increase in BZD doses, as the prescription rates and proportions of patients receiving at least two drugs for MRA and ORA were low. Patients who received second and third drugs were prescribed higher doses from the start of treatment than those only receiving one drug. From a clinical perspective, the risk of future complications is substantial if high-dose BZD is required from the start of treatment $[1,3,5]$; therefore, multifaceted interventions including non-drug therapy should be considered.

This analysis is limited by its retrospective and observational nature and use of only one medical claims database. The MDV database comprised patients treated at large acute-care hospitals in Japan; therefore, the findings may not be generalisable to patients outside Diagnostic Procedure Combination hospitals. Another limitation associated with the use of the MDV database is the absence of data linkage between medical care facilities, thus some of the patients included in this study may include those who have previously received hypnotic drugs in another facility (not new starters). Statistical comparisons were not conducted in this study. The study population includes only those patients from the MDV database who were prescribed at least one hypnotic drug, which was a small proportion (14.6\%) of the database. Furthermore, no information on non-pharmacological sleep interventions (cognitive-behavioural therapy, relaxation methods, sleep hygiene) or the relative effectiveness of treatments is available. Additionally, findings are only applicable to the hospital setting; therefore, conducting a similar analysis using data including the primary care setting would be important.

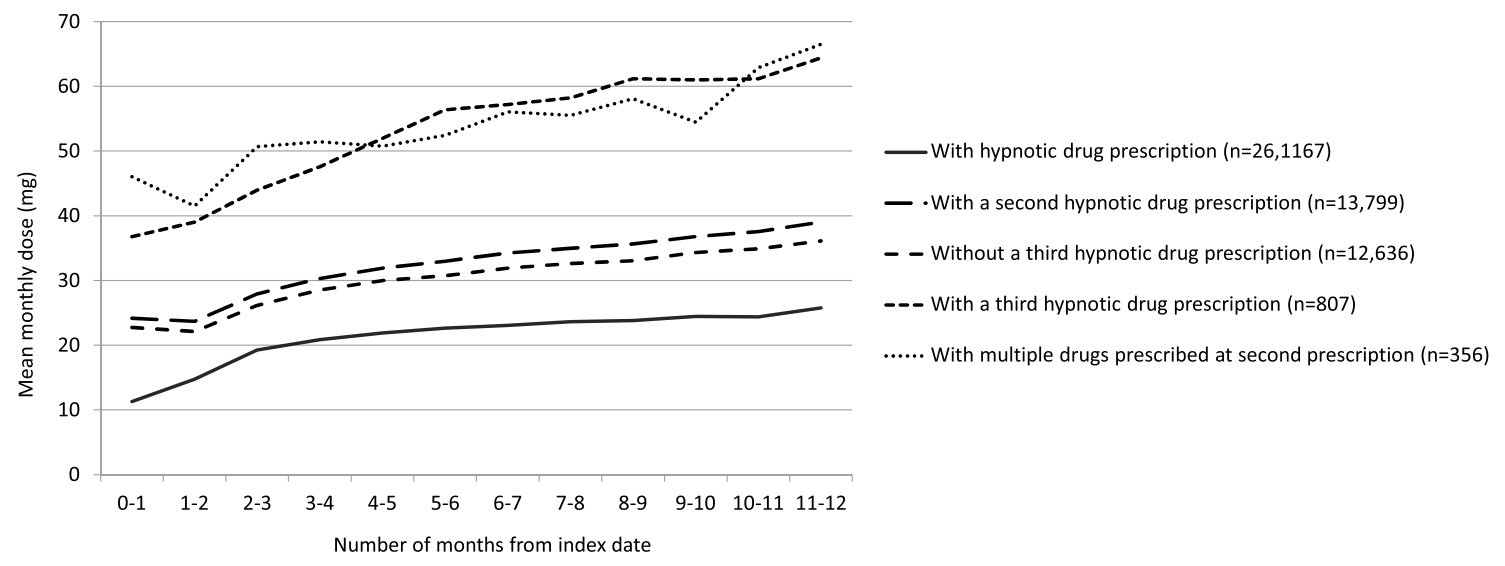

Fig. 3 Mean monthly dose of prescribed hypnotic medication (flunitrazepam dose equivalent) over time elapsed since the first hypnotic drug prescription (index date), according to subsequent prescriptions 


\section{Conclusions}

Patients prescribed a first hypnotic drug in hospitals in Japan most commonly receive a BZD or non-BZD, with prescriptions more frequent in inpatients than in outpatients. Further education and awareness may be needed around the risk of complications and adverse events associated with these therapies. In accordance with prescribing guidelines, BZDs and non-BZDs were mostly prescribed for shorter durations than the MRA and ORA. The MRA and ORA were more likely to be prescribed as a first hypnotic drug within internal medicine, psychiatry and neurology/neurosurgery departments. Long-term use and co-prescribing of hypnotic medications were uncommon.

Acknowledgements The authors thank Shuichi Okamoto and Manami Yoshida of Takeda Pharmaceutical Company Limited, and Kosuke Iwasaki of Milliman Inc., for their invaluable contributions to this study. The authors also acknowledge Catherine Crookes and Mai Kurihara of FireKite, an Ashfield company, part of UDG Healthcare plc, for writing support during the development of this manuscript, which was funded by Takeda Pharmaceutical Company Limited (Tokyo, Japan), and complied with Good Publication Practice 3 ethical guidelines.

\section{Declarations}

Funding Takeda Pharmaceutical Company Limited (Tokyo, Japan) funded this study, assisted with the preparation of this manuscript and will sponsor open access of the published article.

Conflict of interest Ken Inada reports research grants from MSD and speaker's honoraria from Eisai, Eli Lilly, Janssen, Otsuka Pharmaceutical Company, Shionogi, Mitsubishi Tanabe Pharma, Sumitomo Dainippon Pharma, Novartis, Pfizer, Meiji Seika Pharma, MSD, Yoshitomiyakuhin Corporation and Mochida Pharmaceutical Company. Minori Enomoto has no conflicts of interest that are directly relevant to the content of this article. Kentaro Yamato is an employee of Takeda Pharmaceutical Company Limited. Kazuo Mishima reports public research funds from the Japanese Ministry of Health, Labour and Welfare (H29-Seishin-Ippan-001, 19GC1012) and the Japanese Ministry of Education, Science, and Technology (19H03578), research grants from Eisai Co., Ltd., Nobelpharma Co., Ltd., Otsuka Pharmaceutical Co., Ltd. and Takeda Pharmaceutical Co., Ltd, and speaker's honoraria from Eisai Co., Ltd., MSD Inc., Takeda Pharmaceutical Co., Ltd., Astellas Pharma Inc., Pfizer Inc., Otsuka Pharmaceutical Co., Ltd., Mochida Pharmaceutical Co., Ltd., Mitsubishi Tanabe Pharma Corporation (Yoshitomiyakuhin Corporation) and Janssen Pharmaceutical.

Ethics approval This was a retrospective analysis of data within a nationwide claims database managed by Medical Data Vision Co., Ltd, Tokyo, Japan. Because of the anonymous nature of the analysis and the absence of direct patient involvement, no ethical approval or patient consent was required for the present study in the authors' institutions. Medical Data Vision Co., Ltd collect and use patients' personal data and anonymously processed information in accordance with regulations including the Japanese Act on the Protection of Personal Information and the European Union's General Data Protection Regulation.

Consent to participate Not applicable.

Consent for publication Not applicable.
Availability of data and material Data used in this study are not available publicly. The anonymised insurance data, which can be used for secondary research, can be accessed upon request to MDV (https:// www.mdv.co.jp/).

Cod availability Not applicable.

Authors' contributions The authors critically reviewed all drafts of the manuscript and approved the final version for submission. KI is a psychiatric expert and was involved in the planning of the study and interpretation of the results. KM is a sleep medicine specialist and was involved in study planning and study approval. KY contributed to the development of the research plan, the management of the research and interpretation of the results. ME is a sleep assessment specialist and was involved with research planning, analytical advice and results interpretation.

Open Access This article is licensed under a Creative Commons Attribution-NonCommercial 4.0 International License, which permits any non-commercial use, sharing, adaptation, distribution and reproduction in any medium or format, as long as you give appropriate credit to the original author(s) and the source, provide a link to the Creative Commons licence, and indicate if changes were made. The images or other third party material in this article are included in the article's Creative Commons licence, unless indicated otherwise in a credit line to the material. If material is not included in the article's Creative Commons licence and your intended use is not permitted by statutory regulation or exceeds the permitted use, you will need to obtain permission directly from the copyright holder. To view a copy of this licence, visit http://creativecommons.org/licenses/by-nc/4.0/.

\section{References}

1. Asnis GM, Thomas M, Henderson MA. Pharmacotherapy treatment options for insomnia: a primer for clinicians. Int J Mol Sci. 2015;17(1):50. https://doi.org/10.3390/ijms17010050.

2. Qaseem A, Kansagara D, Forciea MA, Cooke M, Denberg TD. Management of chronic insomnia disorder in adults: a clinical practice guideline from the American College of Physicians. Ann Intern Med. 2016;165(2):125-33. https://doi.org/10.7326/ m15-2175.

3. Riemann D, Baglioni C, Bassetti C, Bjorvatn B, Dolenc Groselj L, Ellis JG, et al. European guideline for the diagnosis and treatment of insomnia. J Sleep Res. 2017;26(6):675-700. https://doi. org/10.1111/jsr.12594.

4. Sateia MJ, Buysse DJ, Krystal AD, Neubauer DN, Heald JL. Clinical practice guideline for the pharmacologic treatment of chronic insomnia in adults: an American Academy of Sleep Medicine clinical practice guideline. J Clin Sleep Med. 2017;13(2):307-49. https://doi.org/10.5664/jcsm.6470.

5. Neubauer DN, Pandi-Perumal SR, Spence DW, Buttoo K, Monti JM. Pharmacotherapy of insomnia. J Cent Nerv Syst Dis. 2018;10:1179573518770672. https://doi.org/10.1177/1179573518 770672.

6. Ministry of Health, Labour and Welfare, Tokyo, Japan. Public notice no. 107. 2006. https://www.mhlw.go.jp/web/t_doc?dataI $\mathrm{d}=84$ aa7837\&dataType $=0$ \&pageNo=1. Accessed Mar 2019.

7. Ministry of Health, Labour and Welfare Tokyo, Japan. Outline of FY 2014 revision of medical fee. 2014. https://www.mhlw.go.jp/ file/06-Seisakujouhou-12400000-Hokenkyoku/0000039891.pdf. Accessed Mar 2019.

8. Ministry of Health, Labour and Welfare, Tokyo, Japan. Public notice no. 365. 2016. https://kouseikyoku.mhlw.go.jp/kinki/ 
iryo_shido/documents/281013_keijijikou_kokuji.pdf. Accessed Mar 2019.

9. Ministry of Health, Labour and Welfare, Tokyo, Japan. Public notice no. 97. 2008. https://www.mhlw.go.jp/topics/2008/03/dl/ tp0305-1ci.pdf. Accessed Mar 2019.

10. Ministry of Health, Labour and Welfare, Tokyo, Japan. The duration of prescription of oral medicine designated as a new psychotropic drug. 2016. https://www.city.arakawa.tokyo.jp/docum ents/7388/20160914-kouseishinyaku.pdf. Accessed Mar 2019.

11. Japanese Society of Sleep Research, Tokyo, Japan. Clinical guidelines for proper use of sleeping pills and drug withdrawal. 2013. http://www.jssr.jp/data/pdf/suiminyaku-guideline.pdf. Accessed Mar 2019.

12. Okumura Y, Shimizu S, Matsumoto T. Prevalence, prescribed quantities, and trajectory of multiple prescriber episodes for benzodiazepines: a 2-year cohort study. Drug Alcohol Depend. 2016;158:118-25. https://doi.org/10.1016/j.drugalcdep .2015.11.010.

13. Inada T, Inagaki A. Psychotropic dose equivalence in Japan. Psychiatry Clin Neurosci. 2015;69(8):440-7. https://doi.org/10.1111/ pcn. 12275 .

14. Mishima K, DiBonaventura M, Gross $\mathrm{H}$. The burden of insomnia in Japan. Nat Sci Sleep. 2015;7:1-11. https://doi.org/10.2147/nss. S73437.

15. Lee MH, Choi JW, Lee J, Shin A, Oh SM, Jung SJ, et al. Trends in prescriptions for sedative-hypnotics among Korean adults: a nationwide prescription database study for 2011-2015. Soc Psychiatry Psychiatr Epidemiol. 2019;54(4):477-84. https://doi. org/10.1007/s00127-018-1615-x.

16. Bertisch SM, Herzig SJ, Winkelman JW, Buettner C. National use of prescription medications for insomnia: NHANES 1999-2010. Sleep. 2014;37(2):343-9. https://doi.org/10.5665/sleep.3410.

17. Dai YX, Chen MH, Chen TJ, Lin MH. Patterns of psychiatric outpatient practice in Taiwan: a nationwide survey. Int J Environ Res Public Health. 2016;13(10):955. https://doi.org/10.3390/ijerp h13100955.

18. Gerardin M, Rousselet M, Caillet P, Grall-Bronnec M, Loue P, Jolliet $\mathrm{P}$, et al. French national health insurance database analysis and field study focusing on the impact of secure prescription pads on zolpidem consumption and sedative drug misuse: ZORRO study protocol. BMJ Open. 2019;9(6):e027443. https://doi.org/10.1136/ bmjopen-2018-027443.

19. Schneider R, Reinau D, Schur N, Blozik E, Fruh M, Signorell A, et al. Drug prescription patterns, polypharmacy and potentially inappropriate medication in Swiss nursing homes: a descriptive analysis based on claims data. Swiss Med Wkly. 2019;149:w20126. https://doi.org/10.4414/smw.2019.20126.

20. Nakao M, Takeuchi T, Yano E. Prescription of benzodiazepines and antidepressants to outpatients attending a Japanese university hospital. Int J Clin Pharmacol Ther. 2007;45(1):30-5.

21. Krystal AD. Psychiatric disorders and sleep. Neurol Clin. 2012;30(4):1389-413. https://doi.org/10.1016/j.ncl.2012.08.018.

22. Schwarzbold M, Diaz A, Martins ET, Rufino A, Amante LN, Thais ME, et al. Psychiatric disorders and traumatic brain injury. Neuropsychiatr Dis Treat. 2008;4(4):797-816.

23. Huang WF, Lai IC. Patterns of sleep-related medications prescribed to elderly outpatients with insomnia in Taiwan. Drugs Aging. 2005;22(11):957-65. https://doi.org/10.2165/00002512200522110-00005.

24. Miyamoto M, Hirata K, Miyamoto T, Iwase T, Koshikawa C. Hypnotic prescriptions in a university hospital: analysis of data from the computer-ordering system. Psychiatry Clin Neurosci. 2002;56(3):305-6. https://doi.org/10.104 6/j.1440-1819.2002.01007.x.
25. Nomura K, Nakao M, Sato M, Yano E. Regular prescriptions for benzodiazepines: a cross-sectional study of outpatients at a university hospital. Intern Med. 2006;45(22):1279-83.

26. Kesselheim AS, McGraw SA, Dejene SZ, Rausch P, Dal Pan GJ, Lappin BM, et al. Patient and physician perceptions of drug safety information for sleep aids: a qualitative study. Drug Saf. 2017;40(6):531-42. https://doi.org/10.1007/s40264-017-0516-3.

27. Bourcier E, Korb-Savoldelli V, Hejblum G, Fernandez C, Hindlet P. A systematic review of regulatory and educational interventions to reduce the burden associated with the prescriptions of sedative-hypnotics in adults treated for sleep disorders. PLoS One. 2018;13(1):e0191211. https://doi.org/10.1371/journal.pone.01912 11.

28. Cunningham CM, Hanley GE, Morgan S. Patterns in the use of benzodiazepines in British Columbia: examining the impact of increasing research and guideline cautions against long-term use. Health Policy. 2010;97(2-3):122-9. https://doi.org/10.1016/j.healt hpol.2010.03.008.

29. Davies J, Rae TC, Montagu L. Long-term benzodiazepine and Z-drugs use in England: a survey of general practice. Br J Gen Pract. 2017;67(662):e609-13. https://doi.org/10.3399/bjgp1 7 X691865.

30. Hata T, Kanazawa T, Hamada T, Nishihara M, Bush AI, Yoneda $\mathrm{H}$, et al. What can predict and prevent the long-term use of benzodiazepines? J Psychiatr Res. 2018;97:94-100. https://doi. org/10.1016/j.jpsychires.2017.11.012.

31. Hirooka T. Excessive prescribing of hypnotic and anxiolytic drugs in Japan. Nihon Rinsho. 2015;73(6):1049-56.

32. Jacob L, Rapp MA, Kostev K. Long-term use of benzodiazepines in older patients in Germany: a retrospective analysis. Ther Adv Psychopharmacol. 2017;7(6-7):191-200. https://doi. org/10.1177/2045125317696454.

33. Kurko TA, Saastamoinen LK, Tahkapaa S, Tuulio-Henriksson A, Taiminen T, Tiihonen J, et al. Long-term use of benzodiazepines: definitions, prevalence and usage patterns: a systematic review of register-based studies. Eur Psychiatry. 2015;30(8):1037-47. https ://doi.org/10.1016/j.eurpsy.2015.09.003.

34. Nomura K, Nakao M, Sato M, Yano E. The long-term prescription of benzodiazepines, psychotropic agents, to the elderly at a university hospital in Japan. Tohoku J Exp Med. 2007;212(3):239-46.

35. Sakshaug S, Handal M, Hjellvik V, Berg C, Ripel A, Gustavsen $\mathrm{I}$, et al. Long-term use of Z-hypnotics and co-medication with benzodiazepines and opioids. Basic Clin Pharmacol Toxicol. 2017;120(3):292-8. https://doi.org/10.1111/bcpt.12684.

36. Takeshima N, Ogawa Y, Hayasaka Y, Furukawa TA. Continuation and discontinuation of benzodiazepine prescriptions: a cohort study based on a large claims database in Japan. Psychiatry Res. 2016;237:201-7. https://doi.org/10.1016/j.psychres.2016.01.040.

37. Uchiyama M, Hamamura M, Kuwano T, Nishiyama H, Nagata $\mathrm{H}$, Uchimura N. Evaluation of subjective efficacy and safety of ramelteon in Japanese subjects with chronic insomnia. Sleep Med. 2011;12(2):119-26. https://doi.org/10.1016/j.sleep.2010.08.010.

38. Abe S, Enomoto M, Kitamura S, Hida A, Tachimori H, Tsutsui $\mathrm{T}$, et al. Prescription hypnotics and associated background factors in a large-scale Japanese database. Sleep Biol Rhythms. 2012;10(4):319-27. https://doi.org/10.111 $1 / j .1479-8425.2012 .00573 . x$.

39. Pharmaceuticals and Medical Devices Agency. Dependence associated with benzodiazepine receptor agonists. PMDA alert for proper use of drugs. 2017. https://www.pmda.go.jp/files/00021 7228.pdf. Accessed Jan 2021. 


\section{Authors and Affiliations}

\section{Ken Inada $^{1}\left(\mathbb{D} \cdot\right.$ Minori Enomoto $^{2}(\mathbb{D}) \cdot$ Kentaro Yamato $^{3}(\mathbb{D}) \cdot$ Kazuo Mishima $^{4,5,6}$ (D)}

1 Department of Psychiatry, Tokyo Women's Medical University, Tokyo, Japan

2 Department of Medical Technology, School of Health Sciences, Tokyo University of Technology, Tokyo, Japan

3 Japan Medical Affairs, Takeda Pharmaceutical Company Limited, Tokyo, Japan

4 Department of Neuropsychiatry, Akita University Graduate School of Medicine, Akita, Japan
5 Department of Psychophysiology, National Institute of Mental Health, National Center of Neurology and Psychiatry, Tokyo, Japan

6 International Institute for Integrative Sleep Medicine, Tsukuba, Japan 